\title{
A carreira de Especialistas em Políticas Públicas e Gestão Governamental de Minas Gerais e os desafios de retenção: análise comparativa de 2009 e 2019
}

\section{Kamila Pagel de Oliveira}

Fundação João Pinheiro, Belo Horizonte, MG - Brasil

Ivan Beck Ckagnazaroff

Universidade Federal de Minas Gerais, Belo Horizonte, MG - Brasil

\section{Mauro César da Silveira}

Fundação João Pinheiro, Belo Horizonte, MG - Brasil

Este artigo analisa os principais motivos que levavam à evasão dos Especialistas em Políticas Públicas e Gestão Governamental do Estado de Minas Gerais até o ano de 2009, bem como as mudanças introduzidas a partir da Lei no 18.974/2010 e seu reflexo na retenção desses profissionais. Trata-se de um estudo de caso que contou com coleta de dados em dois momentos distintos, 2009 e 2019. Para análise da evasão, foram aplicados questionários aos EPPGG, membros e exonerados, além da realização de entrevistas com os EPPGG e com os gestores da carreira, realizadas em 2009. Em 2019, foi realizada pesquisa documental que possibilitou a atualização dos dados referentes à evasão, remuneração e alocação dos profissionais. Os resultados indicam que as mudanças introduzidas desde 2010, a partir da referida lei, influenciaram a retenção dos EPPGG, tendo em vista que trouxeram significativas mudanças nos dois principais motivos que levavam à evasão dos ocupantes deste cargo, sendo eles, falhas na estrutura da carreira e inadequação no que tange à remuneração desses profissionais.

Palavras-chave: profissionalização, evasão, EPPGG 


\section{La carrera de Especialistas en Políticas Públicas y Gestión Gubernamental en Minas Gerais y los desafíos de la retención: análisis comparativo de 2009 y 2019}

Este artículo analiza las principales razones de la evasión de Especialistas en Políticas Públicas y Gestión del Gobierno de Minas Gerais, hasta 2009 y los cambios realizados desde la Ley N 18.974 / 2010 y sus efectos sobre la retención de estos profesionales. Este es un estudio de caso que incluyó el análisis de datos en dos momentos distintos, 2009 y 2019. Para el análisis de evasión, fueron hechas encuestas a los miembros EPPGG y a los exonerados, así como entrevistas con los gerentes EPPGG y de carrera, llevadas a cabo en 2009. En 2019, se realizó una investigación documental que permitió actualizar los datos sobre evasión, remuneración y asignación de profesionales. Los resultados indican que los cambios introducidos desde 2010, a partir de la ley referida, influyeron a la retención de EPPGG, considerando que trajeron cambios significativos en las dos principales razones que llevaron a la evasión de los ocupantes de esta posición, que son, defectos en la estructura de la carrera y inadecuación con respecto a la remuneración de estos profesionales.

Palabras clave: profesionalización, EPPGG, evasión de profesionales

The career of Specialists in Governmental Management and Public Policies in Minas Gerais and the challenges of retention: comparative analysis of 2009 and 2019

This article analyzes the main reasons leading evasion of Specialists in Public Policies and Government Management of Minas Gerais, by the year 2009 and the changes made from the Law no 18.974 / 2010 and its possible contribution to the retention of these professionals. It is a case study that included data collection at two different times, 2009 and 2019. For analysis of evasion, questionnaires were given to dismissed and members, as well as interviews with EPPGG and career managers, carried out in 2009. In 2019, documentary research was carried out, which made it possible to update data on evasion, remuneration and allocation of professionals. The results indicate that the changes introduced since 2010 influenced to the retention of EPPGG, given that brought significant changes in the two main reasons that led to the escape of the occupants of this position, they are, flaws in the career structure and inadequacy regarding the remuneration.

Keywords: professionalization, EPPGG, evasion of professionals 


\section{Introdução}

A Reforma do Estado se tornou tema amplamente discutido em todo o mundo, a partir, principalmente, da década de 1980. Esse movimento pode ser interpretado como uma resposta à crise do Estado, no contexto de uma economia globalizada. A redução da autonomia do Estado na formulação e implantação de políticas públicas, provocada pelo processo de globalização e pela crise econômica e fiscal, evidenciou a necessidade de redefinir as funções do Estado, motivando a realização de processos de reforma (ABRUCIO, 1997; Pereira, 1998; Carneiro; Menicucci, 2011).

Uma das principais iniciativas de Reforma do Estado, que começou a ocorrer a partir da década de 1980, referia-se a modificações nas políticas de recursos humanos. A preocupação central inicialmente, quanto a essa área, esteve relacionada à necessidade de reduzir a folha de pagamentos e de priorizar o enxugamento da máquina administrativa em detrimento da reformulação de políticas de gestão de pessoas que conferissem relevância no que tange à profissionalização e ao desenvolvimento das pessoas. Tal foco se deveu às pressões pela redução do aparato do Estado e dos gastos públicos com pessoal, caracterizando-se como medida essencial à reestruturação das finanças públicas, tendo em vista o momento de crise fiscal e de questionamentos acerca do modelo de gestão burocrático, sinalizado em diversos países (NOGUEIRA, 2002; LONGO, 2007; RAMIÓ, 2008).

A partir da década de 1990, após a percepção de que as políticas de downsizing não alcançaram os objetivos de eficiência e modernização pretendidos pelas reformas do setor público, em um segundo momento, a atenção voltou-se para a reformulação das políticas de gestão de pessoas, com base no entendimento de que as efetivas mudanças na qualidade dos serviços públicos somente ocorreriam por meio de investimentos em profissionalização e desenvolvimento da força de trabalho (GAETANI, 1998; NogUEIRA, 2002; LONGO, 2007; RAMIó, 2008).

De acordo com Figueroa (2002), a promoção de maior profissionalização no setor público demanda a implementação de políticas relacionadas à estruturação dos sistemas de direção, das formas de contratação, recrutamento, seleção e nomeação, bem como a criação de formas de desenvolvimento e retribuição, por meio da avaliação de desempenho, 
da remuneração e das políticas de mobilidade e capacitação. Abrucio (2007) afirma que a profissionalização da burocracia passa pela redefinição e fortalecimento das carreiras de Estado e pelo aumento do investimento em capacitação dos servidores públicos. Em Minas Gerais, um esforço de profissionalização pode ser observado a partir da criação do Curso de Administração Pública da Escola de Governo da Fundação João Pinheiro (Csap), em 1986, cujo objetivo é formar profissionais qualificados para atuar em gestão governamental e na formulação, implementação e avaliação de políticas públicas no Estado de Minas Gerais. Esses profissionais ocupariam o cargo de Administrador Público, carreira criada também em 1986 e que, a partir de 2004, passou a ser denominada de Especialista em Políticas Públicas e Gestão Governamental. O Csap é, portanto, o responsável pela formação do EPPGG, cujo ingresso ocorre por meio de concurso público. Ao término do curso, os aprovados são nomeados para o cargo em questão e passam a atuar em algum dos órgãos da administração direta ou indireta do Estado de Minas Gerais, em sua maioria, alocados em funções estratégicas e diretivas do estado. Tratou-se, à época, de uma experiência pioneira e que ainda preserva seu caráter inovador, tendo em vista ser a única experiência no país que articula a formação em um curso de graduação com o ingresso em uma carreira pública.

Além do ingresso automático em uma carreira pública, o Csap ainda possui como benefícios: a gratuidade do curso; o recebimento pelos alunos de uma bolsa de estudos no valor de um salário mínimo, ao longo dos quatro anos de estudo; e a qualidade do curso reconhecida pelas principais avaliações do Ministério da Educação, em que frequentemente se posiciona como um dos melhores cursos de administração do país.

Não obstante tais benefícios, detectava-se, até o ano de 2009, um significativo percentual de evasão desses profissionais, alcançando naquele ano o índice de 35,9\%. Tal evasão trazia prejuízos não apenas financeiros, dado o investimento realizado no EPPGG ao longo de sua formação no Csap, mas principalmente para o projeto de profissionalização da gestão pública mineira, já que significava a perda de profissionais altamente qualificados (CRUZ, 2005; OliveirA, 2009).

Em atenção a esse contexto, o Estado de Minas Gerais publicou em junho de 2010 a Lei $n$ ㅇ 18.974, que introduziu mudanças significativas na estrutura da carreira de EPPGG, instituindo um inovador sistema de pontuação para a obtenção de progressão e 
promoção, com base na valorização de diversos aspectos para o crescimento na carreira, para além do tempo de serviço.

O objetivo deste trabalho consiste em analisar a carreira de EPPGG em relação aos principais motivos que levavam à evasão dos EPPGG até o ano de 2009, bem como as mudanças introduzidas a partir da Lei no 18.974/2010 e seu reflexo na retenção desses profissionais, a partir da análise de dados de evasão e dados de gestão da carreira de 2019. Buscou-se responder às seguintes questões: Quais eram os motivos que levavam à evasão de EPPGG do Estado de Minas Gerais até o ano de 2009? Quais são as influências da referida lei na retenção desses profissionais?

A criação da carreira de EPPGG possui relevância histórica, sendo considerada uma importante iniciativa da administração pública brasileira direcionada à modernização e profissionalização da gestão pública, presente no Governo Federal e em diversos estados (Klein; Mascarenhas, 2016). Apesar disso, para Klein e Mascarenhas (2016, p. 24), “a consolidação dessa carreira vem sendo um desafio contínuo, principalmente nos governos estaduais", já que, apesar das competências de atuação desafiadoras e da relevância das atribuições, observam-se elevados índices de evasão e insatisfação de seus profissionais em algumas dessas experiências.

A carreira em Minas Gerais, uma das primeiras a serem criadas no país, está associada à formação de um corpo profissional qualificado que pode atuar tanto na área meio do Estado quanto na formulação e implementação de políticas públicas, nas mais diversas áreas da administração pública. Dado esse caráter pioneiro na implementação de uma política de carreira inovadora, natural que esse projeto seja suscetível a revisões e transformações.

Diante desse cenário, compreender melhor esse contexto, a carreira de EPPGG e as necessidades de reajustes nas políticas destinadas a esses profissionais pode auxiliar na gestão não apenas da carreira de EPPGG de Minas Gerais, mas dos demais estados, contribuindo para o projeto de profissionalização da gestão pública brasileira. 


\section{A importância da retenção de profissionais qualificados para a profissionali- zação do setor público}

Com as transformações iniciadas a partir da década de 1980, orientadas para a reforma do Estado, a área de gestão de pessoas passou a ser vista como uma área que carecia de mudanças. Nesse momento, em conformidade com as premissas neoliberais, intensificaram-se as pressões por Reformas do Estado, que significavam a redução do aparato governamental e apontavam para a redução dos gastos públicos com pessoal, caracterizando-se como medida essencial à reestruturação das finanças públicas e à reforma gerencial (GAETANI, 1998; CARNeIRO; MENICUCCI, 2011). No Brasil, foi apresentado, em 1995, o Plano Diretor da Reforma do Aparelho do Estado que teve como objetivos fundamentais o fortalecimento da capacidade de gestão do Estado e a busca pela modernização da administração pública. Apesar das críticas apontadas por diversos autores quanto aos limites da Nova Gestão Pública, tais como reforço da separação entre política e administração, desconsideração pela dimensão sociopolítica da gestão, foco intraorganizacional, e ações pouco democráticas (RHODES, 1996, BRUGUÉ, 2004; Paula, 2005; Gomes, 2009; Denhardt ; Denhardt, 2000; Carneiro; Menicucci, 2011), pode-se afirmar que a partir das iniciativas de reforma, maior ênfase passou a ser dada à área de gestão de pessoas e à profissionalização da gestão pública, que passa a ser tratada como um dos principais pilares para a melhoria da qualidade do serviço público em diversos países que passavam por processos similares, inclusive no Brasil. (Gaetani, 1998; Nogueira; Santana, 2002; Abrúcio, 2007; Ramió, 2008).

A profissionalização do serviço público está relacionada a questões como: melhoria dos processos de seleção dos funcionários; orientação ao cumprimento das demandas da sociedade, gestão voltada para mérito e resultados; capacitação e treinamento de servidores; busca constante pela eficiência, pela transparência e pela accountability; valorização das diferentes competências e contribuições dos profissionais; profissionalização do alto escalão governamental; redefinição e fortalecimento das carreiras estratégicas do Estado (VIANA, 2007; ABRUCIO, 2007; PACHECO, 2010; FARIA et al., 2012). 
Diante desse novo contexto organizacional de busca por maior profissionalização da gestão pública, em que as pessoas são o foco principal para a melhoria da qualidade do serviço público, um desafio das organizações gira em torno de como motivar e reter profissionais qualificados e ainda investir de forma continuada em sua capacitação (LONGO, 2007).

De acordo com Klein e Mascarenhas (2016), a preocupação com o grau de satisfação, taxa de rotatividade e percentual de evasão dos profissionais é constante em qualquer organização. Os autores salientam que nem toda evasão é ruim, mas passa a ser um problema quando profissionais talentosos, com experiência e detentores de conhecimentos importantes, saem da organização de forma voluntária, em função de mecanismos inadequados de fatores motivacionais.

Diversas são as políticas de gestão de pessoas percebidas como relevantes para a retenção de pessoas, destacando-se: gestão do desempenho direcionada ao desenvolvimento profissional e crescimento pessoal; busca de maior equidade de remuneração; investimento em formação, treinamento e desenvolvimento da equipe; desenvolvimento de um canal aberto e direto de comunicação entre alta gestão e funcionários; e criação de um clima organizacional favorável (LONGO, 2007; BARRETO, 2008; DUNZER et al., 2008 ).

A pesquisa de Silva (2006) foca a importância da liderança na retenção de pessoas. Além da conscientização por parte dos gerentes de que são os responsáveis pela retenção dos profissionais de sua equipe, esses precisam utilizar ferramentas para o alcance desses objetivos. Essas ferramentas estão relacionadas não às questões como carreira e remuneração, mas também ao estímulo à participação e ao envolvimento do profissional e conhecimento por parte dos gestores acerca das preferências e interesses não monetários dos profissionais. O autor apresenta uma lista de fatores que contribuem para a evasão e para a retenção das pessoas nas organizações (Quadro 1). 
Quadro 1 | Fatores que favorecem a retenção ou evasão de talentos nas organizações

\begin{tabular}{|l|l|}
\hline Fatores que favorecem a RETENÇÃO do talento & Fatores que favorecem a EVASÃO do talento \\
\hline Segurança no trabalho. & $\begin{array}{l}\text { Falta de segurança no emprego e apoio para } \\
\text { realizar o trabalho. }\end{array}$ \\
\hline Equilíbrio entre o trabalho e a vida pessoal. & $\begin{array}{l}\text { Falta de integração entre superiores e } \\
\text { subordinados. }\end{array}$ \\
\hline Ser reconhecido pelo bom trabalho. & Organização não cumpre com as obrigações. \\
\hline Ter treinamento e desenvolvimento. & $\begin{array}{l}\text { Os funcionários não são envolvidos no } \\
\text { processo decisório. As ordens vêm de cima } \\
\text { para baixo. }\end{array}$ \\
\hline $\begin{array}{l}\text { Participar de cultura corporativa alegre e } \\
\text { descontraída que valoriza e que oferece a } \\
\text { aprendizagem contínua para as pessoas. }\end{array}$ & $\begin{array}{l}\text { Ausência de investimento em treinamento e } \\
\text { desenvolvimento de pessoas. }\end{array}$ \\
\hline Ter orgulho da organização que trabalha. & $\begin{array}{l}\text { Insatisfação com o relacionamento entre } \\
\text { os colegas e chefias. Relações abusivas, } \\
\text { desumanizadas, críticas e desiguais. }\end{array}$ \\
\hline $\begin{array}{l}\text { Ter desafios e verificar significado no trabalho } \\
\text { efetuado. }\end{array}$ & $\begin{array}{l}\text { Estilo de liderança autocrática e prepotente, } \\
\text { baseada no autoritarismo e no controle. }\end{array}$ \\
\hline $\begin{array}{l}\text { Remuneração fixa e variável compatível com } \\
\text { a contribuição destinada aos resultados do } \\
\text { negócio. }\end{array}$ & $\begin{array}{l}\text { Salários e benefícios incompatíveis com a } \\
\text { contribuição oferecida para os resultados. }\end{array}$ \\
\hline
\end{tabular}

Fonte: Silva, 2006, p. 71.

No que tange ao setor público, exemplos de políticas para a retenção de profissionais competentes e qualificados podem ser encontrados nos países membros da Organização para Cooperação e Desenvolvimento Econômico (OCDE). Um dos principais problemas identificados no que tange à gestão de pessoas de boa parte desses países, a partir dos anos 1980, foi a queda da competitividade governamental para atração e retenção de profissionais competentes, em comparação com o setor privado, devido aos baixos salários do setor público e à falta de prestígio do serviço público por parte dos jovens formandos e profissionais. Assim, foram adotadas medidas como: revisão das formas e valores da remuneração e dos incentivos praticados no setor público, o que ocorreu no Reino Unido, Suíça, Alemanha, Áustria, Coréia e Nova Zelândia; maior investimento nas políticas de educação e formação dos servidores, percebida na Nova Zelândia e França; melhoria da imagem do serviço público perante os profissionais da nova geração, adotada em países como a Finlândia, Nova Zelândia e Reino Unido (OCDE, 2000). 
Especificamente sobre os Especialistas em Políticas Públicase Gestão Governamental, Klein e Mascarenhas (2016) elencam as seguintes políticas como fundamentais para a retenção desses profissionais: estabelecimento de equidade interna e externa dos incentivos; consolidação de políticas de desenvolvimento da carreira; alocação dos profissionais em atividades compatíveis com a descrição da carreira e de maior impacto social; utilização de políticas adequadas de mobilidade de pessoas; adoção de incentivos à formação e capacitação; e definição de critérios mais atrativos para promoção, progressão e evolução salarial.

Em geral, a ausência de políticas de gestão de pessoas voltadas à retenção dos profissionais está associada ao aumento dos níveis de evasão, além de outros fatores como a maior insatisfação dos profissionais. Sendo assim, a decisão por deixar uma organização ou um cargo pode estar associada a diversos fatores como: ausência de equidade interna e externa; falta de clareza sobre os papéis dos profissionais e sobre a relevância de seu trabalho; ausência de oportunidades de promoção na carreira associadas a oportunidades de trabalho em outras organizações; inadequação das competências do profissional em relação à sua capacidade de atuação e de transformação da realidade em que opera; a fragmentação dos processos de recursos humanos; além da ausência de coerência na gestão da carreira, quando há um desalinhamento entre os processos de atração, seleção, desenvolvimento e promoção destinados a uma carreira (KLEIN; MASCARENHAS, 2016; MотA et al., 2016). Em Minas Gerais, uma importante iniciativa de profissionalização da gestão pública refere-se à formação dos EPPGG pela Escola de Governo da Fundação João Pinheiro, conforme analisada na próxima seção.

\section{A criação da Carreira de EPPGG e a formação pela Escola de Governo}

No intuito de se caracterizar como uma instituição de planejamento no Estado de Minas Gerais, foi criada em 1969 a Fundação João Pinheiro (FJP), com o objetivo de conformar-se como um órgão técnico que pudesse desenvolver um planejamento de estudos sobre a realidade mineira, de modo a atenuar as deficiências econômicas, sociais e administrativas. Nesse momento, um dos temas mais importantes da agenda 
governamental era a busca pelo desenvolvimento econômico, que seria alcançado por meio do planejamento econômico, papel concedido à FJP (AFONSO, 2001).

Influenciado pela criação da Escola Nacional de Administração Pública (Enap) em 1986 e pelo contexto ainda incipiente de reforma do Estado, o Governo de Minas Gerais criou, nesse mesmo ano, o Curso Superior de Administração Pública (Csap), cujo objetivo era a capacitação e a formação de administradores públicos, bem preparados e qualificados, aptos a atuarem na modernização do Estado e na inovação administrativa (Afonso, 2001; HoRTA et al., 2010). Nesse objetivo, foi criado, também em 1986, o cargo de administrador público, que seria ocupado pelos egressos do Csap. Em 1998, o cargo de administrador público foi transformado no cargo de Especialista em Políticas Públicas e Gestão Governamental (EPPGG), sendo essa substituição efetivamente realizada no estado em 2004. As legislações referentes a essa carreira são a Lei no 13.085, de 1998, alterada pela Lei nำ15.304, de 2004, e pela Lei no 18.974 , de 2010.

Até 1992, o Csap foi realizado pelo Centro de Desenvolvimento e Administração (CDA) da FJP. Em 1992, com a criação da escola de governo, o Csap passou a ser oferecido por essa escola, permanecendo até os dias atuais. Inserida na estrutura orgânica da Fundação João Pinheiro, a Escola de Governo de Minas Gerais tem como finalidade constituir um instrumento permanente de modernização e profissionalização da administração pública, conformando-se como um centro responsável pela formação de recursos humanos, por meio de atividades de ensino, relacionada aos cursos de graduação, especialização e mestrado, e em atividades de pesquisa e extensão (AFONSO, 2001; HoRTA et al., 2010).

O Curso de Administração Pública da Escola de Governo constitui a única porta de entrada para a carreira de EPPGG de Minas Gerais, já que apenas os alunos formados nesse curso possuem acesso à referida carreira. Trata-se, portanto, de uma experiência única que possui como pilar a profissionalização da gestão pública.

O Csap possui algumas especificidades em relação aos demais cursos oferecidos no Campo de Públicas, que são percebidas como benefícios e atrativos aos ingressantes. Esses benefícios são a oferta de uma bolsa de estudos mensal, no valor equivalente a um salário mínimo, ou, no caso de alunos que já sejam servidores públicos, o afastamento remunerado do cargo atual para a dedicação exclusiva ao curso; além do ingresso automático, pelo 
aluno formado, no cargo de Especialista em Políticas Públicas e Gestão Governamental (EPPGG) do Estado de Minas Gerais. Tais benefícios conferem ganhos financeiros, além da garantia de uma carreira pública profissional, conferindo aos ingressantes no Csap segurança e estabilidade.

Em contrapartida a esses benefícios, ao ser nomeado, o aluno graduado se compromete a trabalhar no estado, no cargo de EPPGG, durante o período mínimo de três anos. Caso não cumpra esse critério, terá que restituir aos cofres públicos o investimento no valor correspondente aos quatro anos de estudo.

Os EPPGG atuam nos diversos órgãos do Estado de Minas Gerais, desempenhando funções de gestão pública e também de formulação e implementação de políticas públicas. Os EPPGG são constantemente demandados pelas secretarias de Estado, por possuírem formação específica na área pública e, portanto, apresentarem, de forma geral, bons desempenhos em suas atuações e funções (OLIVEIRA et al. 2012).

Um aspecto importante a ser destacado refere-se à qualidade desse Curso de Administração Pública, que se destaca pelo alto conceito perante o Ministério da Educação. A qualidade desse curso é confirmada por meio de avaliações objetivas, tais como o Exame Nacional de Desempenho dos Estudantes (Enade), sendo o melhor Curso de Administração Pública do país, considerando os exames de 2015 e 2018, e o Índice Geral de Cursos (IGC), apresentando, desde a primeira edição, conceito 4 ou 5.

Apesar do êxito percebido no processo de seleção e formação dos EPPGG, que constitui o Csap, a gestão da carreira apresentou alguns desafios de retenção, já que, até o ano de 2009, observava-se uma significativa taxa de evasão dos EPPGG da carreira pública, que ocorria tanto durante o período obrigatório de três anos, como após o término desse período, no qual o EPPGG não precisa mais ressarcir o estado pelo investimento realizado na formação. A evasão até esse ano encontrava-se em um percentual de 35,9\%, conforme pode ser comprovado a partir da Tabela 1. 
Tabela 1 | Percentual de evasão dos EPPGG versus ano de formatura, 2009

\begin{tabular}{|c|c|c|c|c|}
\hline CSAP & Formatura & Graduados & Exonerados & \% evasão \\
\hline I & 1994 & 9 & 6 & $66,70 \%$ \\
\hline II & $1997-$ dez & 27 & 21 & $77,80 \%$ \\
\hline III & $1998-$ jun & 27 & 15 & $55,60 \%$ \\
\hline IV & $1998-$ dez & 31 & 14 & $45,20 \%$ \\
\hline V & $1999-$ dez & 36 & 18 & $50,00 \%$ \\
\hline VI & $2000-$ dez & 32 & 16 & $50,00 \%$ \\
\hline VII & $2001-$ dez & 30 & 12 & $40,00 \%$ \\
\hline VIII & $2002-$ dez & 33 & 18 & $54,50 \%$ \\
\hline IX & $2003-$ dez & 34 & 18 & $52,90 \%$ \\
\hline$x$ & $2004-$ dez & 34 & 7 & $20,60 \%$ \\
\hline$X I$ & $2005-$ dez & 36 & 13 & $36,10 \%$ \\
\hline XII & $2006-$ dez & 34 & 6 & $17,60 \%$ \\
\hline XIII & $2007-$ dez & 33 & 2 & $6,10 \%$ \\
\hline XIV & $2008-$ jun & 36 & 1 & $2,80 \%$ \\
\hline$X V$ & 2008-dez & 33 & 0 & $0,00 \%$ \\
\hline Total & & 465 & 167 & $35,90 \%$ \\
\hline
\end{tabular}

Fonte: elaborada pelos autores, com base em dados disponibilizados pela Escola de Governo e pela Secretaria de Estado de Planejamento e Gestão/MG.

Essa evasão foi considerada elevada, ao ser comparada com outras carreiras do Estado de Minas Gerais, tais como a de gestor fazendário e a de auditor fiscal, semelhante à época no que se refere ao nível de formação, para as quais a evasão era de 17,98\% e $22,71 \%$, respectivamente, conforme informações da Secretaria de Fazenda de Minas Gerais. Coelho explica a evasão observada naquele momento da seguinte forma:

No caso dos egressos da FJP o obstáculo não é a entrada destes no Estado, mas a sua retenção na carreira de EPPGG - no governo do Estado de Minas Gerais após os dois anos exigidos por lei. A insatisfação com a remuneração e a rigidez de promoção leva alguns desses profissionais recém-formados a buscarem, por meio de concurso público, colocações em carreiras federais. Mas há também aqueles que, desmotivados com o setor público-estatal, acabam migrando para a iniciativa privada. (COELHO, 2008, p. 18). 
Não obstante a qualidade e os benefícios da formação oferecida pelo Csap, a percepção dos egressos era de que a carreira de EPPGG não condizia com a qualidade do curso, em função da ausência de políticas de gestão de pessoas bem estruturadas e direcionadas para os ocupantes desse cargo. Conjugando, portanto, uma formação de alta qualidade e uma estrutura de carreira pouco adequada, o Estado de Minas Gerais mostrava dificuldades em reter seus profissionais, o que ocasionava prejuízos tanto financeiros, tendo em vista o alto investimento que se fazia no aluno ao longo de sua formação, quanto, principalmente, no projeto de profissionalização da gestão pública mineira, tendo em vista a perda de profissionais qualificados para outras instituições (OLIVEIRA et. al., 2012), conforme é analisado a seguir.

\section{Aspectos metodológicos}

Quanto ao tipo, esta pesquisa se caracteriza por seu caráter descritivo, já que objetivou descrever a carreira de EPPGG de Minas Gerais, sob olhar das políticas de gestão de pessoas destinadas a esses profissionais e os impactos na retenção.

Quanto aos meios, é delineada por um estudo de caso. Segundo Yin (2010, p. 39), “o estudo de caso é uma investigação empírica que investiga um fenômeno contemporâneo em profundidade e em seu contexto de vida real, especialmente quando os limites entre o fenômeno e o contexto não são claramente evidentes".

A pesquisa buscou analisar os principais motivos do fenômeno da evasão dos ocupantes do cargo de EPPGG de Minas Gerais, bem como as mudanças introduzidas no contexto de gestão desta carreira, a partir da Lei no 18.974/2010, comparando dois momentos distintos dessa gestão, 2009 e 2019. Enquanto estudo de caso, buscou-se uma melhor compreensão da carreira de EPPGG de Minas Gerais, no sentido de auxiliar na tomada de decisão sobre as políticas e práticas de gestão de pessoas que mais impactam na retenção desses profissionais.

Quanto aos procedimentos técnicos utilizados, destacam-se as pesquisas de campo e documental. O primeiro procedimento diz respeito à realização de uma pesquisa de campo de caráter quantitativo e qualitativo, realizada no ano de 2009. A etapa quantitativa 
ocorreu, por meio de um survey, com uma amostra representativa da população de EPPGG formada pela Escola de Governo da Fundação João Pinheiro, no período de 1992 (I Csap) até 2008 (XV Csap), sendo que 298 ainda eram membros da carreira e 167 eram ex-membros da carreira, sendo, portanto, denominados nesta pesquisa de "exonerados".

A Tabela 2 explicita o universo, a amostra e o quantitativo de respostas obtidas para cada um dos grupos.

Tabela 2 | Universo, amostra e respondentes, 2009

\begin{tabular}{|c|c|c|c|}
\hline Grupo & Universo & Amostra & Respostas obtidas \\
\hline Membros & 298 & 129 & 129 \\
\hline Exonerados & 167 & 72 & 73 \\
\hline Total & 465 & 201 & 202 \\
\hline
\end{tabular}

Fonte: elaborada pelos autores, com dados da pesquisa.

O questionário aplicado foi composto por perguntas relacionadas às políticas de gestão de pessoas implementadas no Estado de Minas Gerais e direcionadas aos EPPGG, bem como o impacto da política na evasão dos EPPGG, utilizando-se de uma escala Likert de três pontos que apresenta uma afirmação autodescritiva, tendo como opção de resposta uma escala de pontos com descrições verbais que contemplam extremos de opções, sendo elas: "Concordo", "Não concordo nem discordo" e "Discordo". Embora possa ser utilizada também uma escala Likert de cinco e sete pontos, que varia conforme o nível de precisão demandado, considerou-se suficiente uma escala de três pontos para a mensuração da intensidade de concordância e de discordância das perguntas formuladas, além do ganho obtido no tempo da coleta da informação, sobretudo, por tratar-se de um questionário amplo.

Para a verificação da relação de dependência entre variáveis (existência da política e impacto na evasão), para análise quantitativa, utilizou-se do conceito de nível de significância, chamado de "valor p". O nível de significância adotado nesta pesquisa foi de 0,05 , o que significa que, considerando a hipótese nula verdadeira, se a probabilidade de um dado efeito é menor que $5 \%$, tem-se um suporte significativo para a hipótese de pesquisa ou alternativa. Assim, segundo Dancey (2006, p. 151), "supondo que a hipótese nula é verdadeira e que a probabilidade de se obter um efeito devido a erro amostral seja menor do que 5\%, então o achado é dito significativo". Assim, quando se encontrou um 
nível de significância menor do que 0,05, considerou-se haver uma relação de dependência entre as variáveis em questão.

Adicionalmente, foram realizadas 12 entrevistas com sujeitos distribuídos em dois grupos distintos: primeiro de EPPGG, membros e exonerados; e o segundo de gestores da carreira de EPPGG. O corpus foi composto da seguinte forma, considerando a posição de cada um dos entrevistados no ano de 2009, quando a pesquisa foi realizada:

a) secretária de Estado de planejamento e gestão; b) subsecretário de gestão subgestor da carreira de EPPGG; c) presidente da Fundação João Pinheiro - diretor da Escola de Governo Professor Paulo Neves de Carvalho; d) presidente da Associação dos Administradores Públicos (Amap) ${ }^{1}$ e membro da carreira de EPPGG; e) quatro EPPGG membros da carreira; d) quatro EPPGG exonerados, ou seja, que já saíram da carreira.

As entrevistas objetivaram captar a percepção dos dois grupos acerca dos motivos da evasão dos EPPGG e dos fatores que poderiam influenciar a retenção deles. As entrevistas ocorreram de 12/8/09 a 17/9/09, foram gravadas e analisadas a partir do programa Atlas ti.

O segundo procedimento diz respeito à pesquisa documental que envolveu a análise de documentos institucionais elaborados pela Secretaria de Estado de Planejamento e Gestão de Minas Gerais (Seplag), responsável pela gestão da carreira selecionada, referentes ao quantitativo de profissionais, à remuneração e dados de alocação.

Também se analisou a atual legislação que regulamenta a carreira, a Lei no 18.974/10, para verificar em que medida as mudanças trazidas por essa legislação contemplavam as disfunções e expectativas encontradas na pesquisa realizada em 2009. Essa análise visou identificar as possíveis influências da alteração legal na retenção dos EPPGG. Por fim, buscaram-se ainda informações no Portal da Transparência de Minas Gerais, para que fossem obtidas informações referentes ao exercício e remuneração dos EPPGG, em julho de 2019. 


\section{Apresentação e análise dos resultados da pesquisa}

A apresentação e análise dos resultados da pesquisa foram divididas em dois momentos, sendo o primeiro relativo ao entendimento acerca dos motivos de evasão dos EPPGG e o segundo à análise das mudanças introduzidas pela Lei no 18.974/10 e os possíveis impactos na retenção desses profissionais.

\subsection{Evasão dos EPPGG}

No que se refere aos motivos da evasão dos EPPGG, 60,3\% dos exonerados atribuíram o salário como principal fator, considerado por muitos como insuficiente, injusto e desigual, se considerado o salário que era concedido no mercado de referência, incluindo tanto o setor público quanto o privado. A questão salarial era vista, naquele momento, como o principal motivo para a evasão dos EPPGG, identificado nas entrevistas realizadas com todos os grupos de entrevistados. A Tabela 3 demonstra os principais motivos para evasão na carreira:

Tabela 3 | Motivo para sair da carreira de EPPGG, 2009

\begin{tabular}{|l|c|c|}
\hline Motivação & Frequência & Percentual \\
\hline Salário & 44 & $60,3 \%$ \\
\hline Perspectiva de carreira & 25 & $34,2 \%$ \\
\hline Outro curso & 2 & $2,7 \%$ \\
\hline Outro motivo & 2 & $2,7 \%$ \\
\hline Total & 73 & $39,7 \%$ \\
\hline
\end{tabular}

Fonte: elaborada pelos autores, dados obtidos a partir de pesquisa de campo realizada em 2009.

As entrevistas abaixo transcritas exemplificam o achado:

Eu acho que o principal motivo para a evasão é mesmo a remuneração, buscar remunerações maiores e lugares onde você possa crescer mais, porque nossa carreira tem um limite de crescimento, e a partir desse limite não tem mais perspectiva. Então, eu acho que é a questão da perspectiva e remuneração. Exonerado $A$ 
Saí porque me surgiu uma oportunidade e pelo fato de não enxergar perspectiva de carreira e de salário condizente com o que eu queria para a minha vida no estado, porque eu gostava muito do trabalho. Exonerado B

Importante ressaltar que $76 \%$ dos membros da carreira que responderam ao questionário possuíam uma renda bruta entre $\mathrm{R} \$ \mathbf{2 . 8 0 1 , 0 0}$ e $\mathrm{R} \$ \mathbf{4 . 0 0 0 , 0 0}$ em 2009, enquanto apenas 20,5\% dos EPPGG exonerados possuíam uma renda bruta nessa faixa. Por outro lado, 5,4\% dos membros recebiam acima de $\mathrm{R} \$ 6.401,00$, enquanto $64,4 \%$ dos exonerados possuíam uma renda bruta superior a esse valor. O que demonstra, de fato, uma ausência de equidade externa, considerando a desproporcionalidade entre os valores recebidos pelos EPPGG no Governo de Minas Gerais e aqueles recebidos por profissionais semelhantes, em termos de competências e atribuições, no mercado de referência.

Ainda no que tange à questão salarial, muitos EPPGG afirmavam que, para se ter uma remuneração melhor, esses precisavam receber cargos comissionados que, embora em sua origem apresente uma função importante, de responsabilização e valorização, pode também indicar uma perda de autonomia do profissional, já que se trata de uma indicação política. Além disso, os entrevistados destacaram que os cargos comissionados em sua maioria são destinados a cargos gerenciais, o que prejudicava os EPPGG que possuíam um perfil técnico. Ainda assim, naquele momento, 70,5\% dos membros da carreira possuíam cargo comissionado.

O segundo maior motivo para evasão dos EPPGG, na percepção dos respondentes exonerados, era a falta de perspectiva da carreira, já indicada na fala do Exonerado A, sendo sinalizada como o principal motivo de evasão por $34,2 \%$ desse grupo da amostra. A fala abaixo exemplifica essa questão:

Eu acho que a evasão é a falta de perspectiva na carreira versus a capacidade do pessoal, porque se também não tem perspectiva na carreira, mas não tem uma formação boa, não haveria evasão. Então, mostra que o pessoal tem capacidade e que tem coisas melhores no que tange à estrutura de carreira. Exonerado $\mathrm{B}$

No que tange à estrutura de carreira, havia reclamações referentes: às dificuldades de promoção e progressão, tais como tempo de serviço e barreiras burocráticas (autorização pela Seplag, publicação de decreto); ao longo tempo demandado para se alcançar níveis 
mais altos da carreira; à ausência de incentivos para o crescimento profissional; além do fato de que os incrementos remuneratórios eram pequenos, quando da mudança de nível. Este se refere também à um problema relacionado à questão salarial, mas que está intimamente relacionado à estrutura de carreira.

Conforme explicado na metodologia, os EPPGG também foram questionados acerca da existência de políticas e práticas de gestão de pessoas implementadas para os ocupantes desse cargo pelo Estado de Minas Gerais. A partir da percepção de existência ou inexistência da política, foi possível identificar em que medida essa impactava a retenção ou evasão, respectivamente. Para se verificar essa relação, utilizou-se do nível de significância, valor $p$, sendo que $p<0,05$ indicava relação de dependência entre as variáveis. Dessa forma, para as políticas que foram consideradas inexistentes pela maioria dos EPPGG respondentes e que possuíam $p<0,05$ em relação à variável evasão, concluiu-se que a ausência destas políticas estava contribuindo para a saída dos EPPGG da carreira.

A Tabela 4 apresenta quais políticas estavam contribuindo para a evasão desses profissionais, além de sinalizar as principais ações propostas nas entrevistas de EPPGG e gestores da carreira para a melhoria dessa situação. Como não foram observadas diferenças significativas em relação à percepção dos EPPGG - membros ou exonerados - e dos gestores da carreira, os motivos foram analisados de forma única. Foram consideradas apenas as variáveis que possuem relação de dependência com a variável permanência na carreira, com valor de $p<0,05$.

Tabela 4 | Políticas que contribuem para a evasão dos EPPGG, 2009

\begin{tabular}{|l|l|}
\hline $\begin{array}{l}\text { Políticas e práticas que estão } \\
\text { contribuindo para a evasão }\end{array}$ & $\begin{array}{l}\text { Ações propostas para o aumento da retenção } \\
\text { conforme sinalização das entrevistas realizadas }\end{array}$ \\
\hline $\begin{array}{l}\text { Ausência de mecanismos de } \\
\text { mobilidade que sejam flexíveis às } \\
\text { demandas dos EPPGG }\end{array}$ & $\begin{array}{l}\text { - Criar legislação que estabeleça regras claras e } \\
\text { uniformes para a autorização de transferência de } \\
\text { EPPGG entre setores e entre órgãos. } \\
\text { - Considerar como um dos principais critérios para a } \\
\text { autorização da transferência o interesse do EPPGG, } \\
\text { o interesse do órgão de destino e a autorização do } \\
\text { órgão de origem. }\end{array}$ \\
\hline
\end{tabular}




\begin{tabular}{|l|l|}
\hline $\begin{array}{l}\text { Melhores condições de trabalho } \\
\text { oferecidas aos não concursados em } \\
\text { detrimento das oferecidas aos EPPGG }\end{array}$ & - Item não mencionado nas entrevistas. \\
\hline $\begin{array}{l}\text { Existência de compressão vertical e } \\
\text { horizontal dos salários }\end{array}$ & $\begin{array}{l}\text { - Reestruturação de cargos e salários dos EPPGG } \\
\text { que contemple melhoria não somente no salário } \\
\text { inicial, mas também nos aumentos concedidos pela } \\
\text { mudança de nível e grau. }\end{array}$ \\
\hline $\begin{array}{l}\text { Existência de barreiras formais para as } \\
\text { progressões e promoções } \\
\text { Maneira como as promoções e } \\
\text { progressões ocorrem }\end{array}$ & $\begin{array}{l}\text { - Reestruturação na carreira que diminua as } \\
\text { exigências quanto à escolaridade e quanto ao tempo } \\
\text { necessário para as mudanças de nível e grau. } \\
\text { - Possibilidade de progressão ou promoção } \\
\text { automática, sem necessidade de publicação de } \\
\text { decreto, quando cumpridas as exigências para as } \\
\text { promoções. } \\
\text { - Criar uma carreira diferenciada das demais, cuja } \\
\text { progressão e promoção ocorram em uma vertente } \\
\text { acadêmica e outra gerencial. }\end{array}$ \\
\hline $\begin{array}{l}\text { Ausência de capacitação que } \\
\text { possibilite a complementação da } \\
\text { formação inicial }\end{array}$ & $\begin{array}{l}\text { - Criar legislação que estabeleça incentivos para } \\
\text { a capacitação dos EPPGG, por meio de cursos de } \\
\text { especialização, mestrado e doutorado, e contemple } \\
\text { regras uniformes para todos os EPPGG. } \\
\text { - Promover a realização de intercâmbios com outros } \\
\text { governos, municipais, estaduais e federal, para a } \\
\text { troca de experiências e capacitação profissional. }\end{array}$ \\
\hline - Item não foi mencionado nas entrevistas \\
\hline
\end{tabular}

Fonte: dados da pesquisa obtidos a partir de entrevistas realizadas em 2009.

No que tange à mobilidade, é importante destacar que, conforme pesquisa documental, a mudança dos EPPGG entre órgãos do estado era aprovada pela Secretaria de Planejamento e Gestão de Minas Gerais. Havia uma reclamação recorrente de que a Seplag criava dificuldades para essa transferência, muitas vezes impedindo que essa acontecesse e reduzindo o grau de mobilidade dos EPPGG.

Como exemplo, no caso dos EPPGG que estavam alocados na Seplag, esses afirmavam que não havia mecanismos flexíveis de mobilidade entre aqueles que manifestaram interesse em mudar de órgão. Como a Seplag, igual a todos os outros órgãos e entidades, precisava de profissionais dessa carreira, muitas vezes para não perder o profissional, 
impedia a sua saída, na perspectiva dos entrevistados, o que criava grande insatisfação. Essa questão pode ser confirmada por meio da seguinte fala:

Quando a pessoa entra na Seplag ela morre lá, e aí ela sai do estado. Eu tenho certeza que a maioria que saiu da carreira de EPPGG estava na Seplag. É uma secretaria que tem uma política de manter a pessoa lá dentro. Outra questão relacionada à mobilidade é que não é levada em consideração a opinião do EPPGG, se ele quer ou não ser transferido para outro órgão. Então, o EPPGG pode pedir para mudar, falar que não está gostando do local onde está e ainda assim ter que permanecer no órgão indesejado. O EPPGG fica no órgão até ele sair do governo. Não aguenta mais e pede exoneração. Então, a mobilidade é um problema sério, que desgasta a relação nesse sentido. Membro B

Além disso, os entrevistados destacaram a desigualdade no tratamento de cada uma das demandas referentes à movimentação dos EPPGG entre os órgãos e entidades do Estado, não havendo um critério para o atendimento das mesmas, motivo pelo qual sugeriram a criação de regras claras para regulamentar esse processo. Klein e Mascarenhas (2016) reforçam a importância da mobilidade para a retenção de EPPGG.

Quanto ao nível de compressão salarial, que se refere à diferença entre o salário inicial e o final de uma carreira, os EPPGG alegavam que o salário final da carreira de EPPGG, assim como o salário inicial eram muito baixos, além de o incremento salarial em cada nível ser também pouco significativo. A fala abaixo transcrita exemplifica essa questão:

Nossa carreira tem quatro níveis e não há um incentivo para a escolaridade adicional. Começa ganhando 2 mil e termina com 4. Com essa situação, eu não sei se tem uma política de cargos e salários. Não sei se há incentivo. Eu não consigo perceber, não. Membro C.

Decorrente desses questionamentos, os EPPGG sinalizaram a necessidade de o Estado realizar uma adequação na política de cargos e salários desses profissionais, incrementando os salários final e inicial, além dos reajustes remuneratórios em cada um dos níveis. Essa medida é importante como uma política de reconhecimento e compensação pela contribuição dada por esses profissionais, mas também porque, nessa situação, atribui-se um peso significativo aos cargos comissionados como instrumento de incentivo e desenvolvimento profissional. A fala abaixo transcrita expõe essa questão: 
Acho que tinha que melhorar bastante o salário, o salário mesmo, porque hoje o EPPGG pode até ganhar melhor, mas, em função de cargo comissionados, o que é muito ruim, é inseguro. Então, tinha que melhorar o salário. Exonerado D

No que tange à questão salarial, Silva (2006) afirma que a ausência de salários e benefícios compatíveis com a contribuição oferecida pelo profissional para os resultados da organização se constitui em um dos principais fatores para a evasão dos profissionais qualificados. Longo (2007) e Barreto (2008) também defendem a importância da equidade salarial, interna e externa, e da compensação justa para a permanência dos profissionais na organização. Dessa forma, embora se saiba que políticas de retenção não devem apenas estar direcionadas ao incremento da remuneração e desenvolvimento de uma carreira, percebe-se a importância da questão salarial e de carreira para a retenção dos EPPGG, conforme destacaram esses profissionais.

Quanto à questão da promoção e progressão na carreira de EPPGG, tem-se que as reclamações estavam relacionadas à dificuldade de progressão, caracterizada tanto pelo tempo necessário quanto pelo limite de progressão salarial, visto que se demorava anos para se alcançar o último nível da carreira e esses processos estavam, sobretudo, relacionados ao tempo de serviço.

Além da necessidade de revisão dos critérios de promoção e progressão, os EPPGG entrevistados, tanto membros quanto exonerados, sinalizaram a importância de valorização de critérios gerenciais e acadêmicos para o crescimento profissional na carreira. Essa percepção se justificava pelo perfil dos EPPGG, sendo que muitos ocupavam cargos comissionados, conforme discutido anteriormente, sinalizando, em alguma medida, um perfil gerencial, mas também muitos EPPGG valorizavam a formação continuada, tanto realizando outros cursos de graduação, como de pós-graduação e mestrado, desenvolvendo um perfil mais técnico e acadêmico. A fala de um dos entrevistados sintetiza essa percepção:

Como que uma carreira embasada no conhecimento, o ponto inicial dela é a formação que o estado dá e o EPPGG não consegue progredir mesmo tendo mestrado ou doutorado? O EPPGG tem uma dificuldade imensa de progredir com a carreira atual. Então, é extremamente desmotivante. O EPPGG se dedica para ampliar seu conhecimento. Isso vai se reverter não é para a Usiminas, Microsoft. Isso 
vai se reverter exclusivamente para o estado. E quando o EPPGG volta para dentro do estado para entregar esse conhecimento, a retribuição é zero. Além disso, se o EPPGG consegue progredir na carreira sem depender da ineficiência da Seplag já é muito bom. Por fim, o arcabouço legal ajuda o estado a ser ineficiente. Então, nós temos que melhorar a legislação para ganharmos esses benefícios. Membro B

Por fim, quanto às questões que estavam contribuindo para a evasão dos EPPGG, destaca-se a ausência de políticas de capacitação estruturadas para os ocupantes desse cargo. Tal questão não apareceu de forma significativa na análise dos resultados quantitativos, mas foi levantada pela maioria dos EPPGG entrevistados. Assim, por meio das entrevistas, identificou-se que havia diferentes experiências quanto ao modo de se trabalhar com a capacitação entre os órgãos nos quais os EPPGG estavam inseridos. Assim, na percepção dos EPPGG entrevistados, o estímulo à capacitação variava de um órgão para o outro ou, ainda, de um EPPGG para o outro, dependendo da atuação e influência de cada um. Ainda, alguns afirmaram que no Estado de Minas Gerais não havia o planejamento de uma capacitação para os EPPGG que visualizasse, de fato, uma melhoria em sua formação, mas, sim, a oferta de cursos considerados como superficiais e básicos para eles. Essas questões são percebidas no seguinte depoimento:

A política de capacitação que eu consigo ver no estado parece muito voltada para corrigir um déficit de nunca ter existido nada. Uns cursos meio em grande escala, de alguns temas sobre gestão, que haviam sumido, mas que não são voltados para a carreira de EPPGG, não atrai ninguém da carreira. Não faz sentido diante da formação que a gente já tem quando sai da FJP. E, tirando isso, acaba se tornando uma estratégia individual. Não existe uma política de capacitação para a carreira. Existe cada gestor buscando a melhoria da sua formação. Membro A

Dessa forma, a proposta de criação de incentivos para a realização de ações que aprofundem ou deem continuidade à qualificação possui importância significativa para essa carreira, tendo em vista que já ingressam no serviço público com uma formação superior de alta qualidade e reconhecimento. Além disso, na perspectiva dos próprios gestores da carreira, trata-se de profissionais que valorizam a formação continuada. Sendo assim, na percepção dos EPPGG entrevistados, maiores incentivos para a continuidade dessa formação teria um importante papel na retenção dos profissionais, não obstante as limitações relacionadas à estrutura de carreira e remuneração. 
Conforme demonstra a Tabela 5, 76,7\% dos EPPGG exonerados que saíram da carreira de Minas Gerais o fizeram em função de outras oportunidades encontradas no setor público, seja em âmbito federal, ou mesmo estadual e municipal, considerando a realização de concursos não apenas no Poder Executivo, mas Judiciário e Legislativo também. Apenas 5,5\% dos exonerados deixaram a carreira por uma oportunidade na iniciativa privada.

Tabela 5 | Motivos externos para saída da carreira de EPPGG, 2009

\begin{tabular}{|c|c|c|}
\hline Motivo & Frequência & Percentual \\
\hline Oportunidade do setor público & 56 & $\mathbf{7 6 , 7}$ \\
\hline Oportunidade na iniciativa privada & 4 & 5,5 \\
\hline Motivo familiar & 1 & 1,4 \\
\hline Outro motivo & 12 & 16,4 \\
\hline Total & $\mathbf{7 3}$ & $\mathbf{1 0 0 , 0}$ \\
\hline
\end{tabular}

Fonte: elaborada pelos autores a partir de dados obtidos em pesquisa de campo realizada em 2009.

Pode-se dizer que a evasão dos EPPGG não estava vinculada a uma incompatibilidade do perfil dos membros da carreira com o trabalho do setor público, mas, sim, a características intrínsecas da carreira de EPPGG.

Outra conclusão importante obtida a partir da pesquisa refere-se ao fato de que grande parte das políticas e práticas de gestão de pessoas implementadas até 2009 pelo Estado de Minas Gerais foi implementada de forma uniforme para todos os servidores do estado, na percepção dos EPPGG entrevistados. Nesse contexto, alguns EPPGG reclamavam por uma diferenciação no tratamento concedido a eles, por se tratar de uma carreira reconhecida ou, ao menos, difundida pelos gestores como estratégica para o Governo de Minas Gerais.

No que tange à demanda por essa diferenciação, pôde-se inferir que o fato de os gestores apresentarem um discurso enfático quanto à importância estratégica desses profissionais, tanto durante a formação no Csap quanto posteriormente na carreira, criava maior expectativa por parte dos EPPGG em relação a um tratamento diferenciado. Não havendo tal diferenciação, estimulava-se a insatisfação e desmotivação e, consequentemente, a evasão dos EPPGG. 
A partir do que foi apresentado até aqui, tem-se que a percepção dos EPPGG acerca das ausências de políticas de gestão de pessoas destinadas a eles, e a consequente evasão da carreira, estavam gerando prejuízos à administração pública mineira, não apenas de ordem financeira, mas, principalmente, para o projeto de modernização da gestão pública, tendo em vista a perda de profissionais qualificados e competentes para outras instituições.

Em função disso, em 2010, o governo de Minas Gerais publicou a Lei no 18.974/10, que mudou substancialmente a estrutura de carreira e salarial. Tendo em vista que o foco das alterações esteve justamente nos três principais pontos de críticas dos profissionais entrevistados - estrutura de carreiras, remuneração e incentivos à formação continuada -, acredita-se que tal alteração influenciou o processo de retenção desses profissionais. A parte seguinte trata dessa percepção.

\subsection{A Lei no 18.974/10 e a sua influência na retenção dos EPPGG}

Em 29/06/2010, posteriormente à realização das entrevistas, foi publicada a Lei no 18.974/10, estabelecendo uma nova estrutura para a carreira de EPPGG. A publicação dessa lei foi uma medida frente aos percentuais e aos motivos de evasão acima discutidos.

A primeira importante alteração refere-se à inclusão no caput da referida lei da expressão "carreira estratégica", referindo-se à carreira de EPPGG. Embora seja uma mudança de valor simbólico, reconhece-se de importante significado, já que os EPPGG reclamavam por uma diferenciação na gestão dessa carreira diante das demais carreiras do Estado, conforme sinalizado a seguir:

Para mim, o que deveria ser feito para reter os EPPGG claramente é descolar o desenho de carreira, política remuneratória e avaliação de desempenho da vala comum. Não acredito que uma carreira especificamente formada para atuar com formulação e avaliação, temas estratégicos de políticas públicas, deva seguir as mesmas regras, seguir o mesmo modelo-padrão das demais carreiras do estado. Se é para tratar igual a todos, para de fazer uma formação diferenciada e contrata igual a todos, faz um concurso direto para uma carreira do mesmo nome, e pronto. Você começa com um tratamento diferenciado na formação e interrompe com esse tratamento logo que entra na carreira. Membro A 
Essa diferenciação na gestão do EPPGG, enquanto uma carreira estratégica do Estado de Minas Gerais, destacou-se pelo estabelecimento de um processo diferenciado de progressão e promoção na carreira, baseado em um sistema de pontos, inovador no Estado de Minas Gerais. Nesse sistema, a experiência profissional, bem como as qualificações acadêmicas são pontuadas e consideradas para o desenvolvimento na carreira. A contagem de pontos para a progressão e promoção inicia-se com a entrada em exercício no cargo, tendo seus efeitos após a conclusão do estágio probatório.

Dessa forma, a progressão do EPPGG passa a ocorrer sempre que o profissional acumular cinco pontos, no limite de três progressões por ano e a promoção sempre que acumular 50 pontos, respeitando o tempo mínimo de quatro anos entre uma promoção e outra. Em geral, os demais cargos efetivos do Estado de Minas Gerais consideram apenas o tempo de serviço para a realização de progressões e promoções e ainda estabelecem um prazo maior do que cinco anos para as promoções. Os critérios estabelecidos para atribuição de pontos para desenvolvimento na carreira, bem como as respectivas pontuações, encontram-se na Tabela 6.

\section{Tabela 6 | Critérios de atribuição de pontos para desenvolvimento na carreira de} EPPGG

\begin{tabular}{|l|c|}
\hline Critérios & Pontuação \\
\hline $\begin{array}{l}\text { Conclusão do estágio probatório, após três anos de efetivo exercício, e } \\
\text { comprovação de aptidão para o cargo por meio do parecer conclusivo } \\
\text { da Avaliação Especial de Desempenho }\end{array}$ & 5 pontos \\
\hline Avaliação de Desempenho Individual satisfatória & 3 pontos \\
\hline Apresentação de diploma de conclusão de outra graduação & 25 pontos \\
\hline $\begin{array}{l}\text { Apresentação de certificado de conclusão de curso de pós-graduação } \\
\text { lato sensu }\end{array}$ & 25 pontos \\
\hline $\begin{array}{l}\text { Apresentação de certificado de conclusão de curso de pós-graduação } \\
\text { stricto sensu em nível de Mestrado }\end{array}$ & 40 pontos \\
\hline $\begin{array}{l}\text { Apresentação de certificado de conclusão de curso de pós-graduação } \\
\text { stricto sensu em nível de Doutorado }\end{array}$ & 50 pontos \\
\hline
\end{tabular}




\begin{tabular}{|l|c|}
\hline $\begin{array}{l}\text { Comprovação de experiência em cargo de chefia ou gerência no Poder } \\
\text { Executivo estadual de quarto nível hierárquico, considerando o tempo } \\
\text { de serviço em um único cargo ou no somatório de dois ou mais cargos, } \\
\text { nos termos do regulamento }\end{array}$ & 5 pontos por ano \\
\hline $\begin{array}{l}\text { Comprovação de experiência em cargo de chefia ou gerência no Poder } \\
\text { Executivo estadual de terceiro nível hierárquico, considerando o tempo } \\
\text { de serviço em um único cargo ou no somatório de dois ou mais cargos, } \\
\text { nos termos do regulamento }\end{array}$ & 7 pontos por ano \\
\hline $\begin{array}{l}\text { Comprovação de experiência em cargo de chefia ou gerência no } \\
\text { Poder Executivo estadual de primeiro ou segundo níveis hierárquicos, } \\
\text { considerando o tempo de serviço em um único cargo ou no somatório } \\
\text { de dois ou mais cargos, nos termos do regulamento }\end{array}$ & 10 pontos por ano \\
\hline $\begin{array}{l}\text { Participação e aprovação em atividades de formação e aperfeiçoamento, } \\
\text { nos termos do regulamento }\end{array}$ & 3 pontos por ano \\
\hline $\begin{array}{l}\text { Apresentação de trabalho relacionado à respectiva área de atuação } \\
\text { em eventos como congressos, simpósios, "workshops" ou similares, } \\
\text { nacional ou internacional }\end{array}$ & 3 pontos \\
\hline $\begin{array}{l}\text { Autoria ou coautoria de artigo científico completo publicado em revista } \\
\text { nacional ou internacional }\end{array}$ & 3 pontos \\
\hline $\begin{array}{l}\text { Autoria ou coautoria de capítulo de livro relacionado à respectiva área } \\
\text { de atuação }\end{array}$ & 3 pontos \\
\hline $\begin{array}{l}\text { Autoria ou coautoria de trabalho vencedor de prêmios de reconhecida } \\
\text { excelência em nível estadual, nacional e internacional }\end{array}$ & 3 pontos \\
\hline
\end{tabular}

Fonte: Lei no 18.974/2010.

Além da diferenciação da carreira de EPPGG em relação às demais, sinalizando seu caráter estratégico, pode-se afirmar também que tal sistema para progressão e promoção considera as especificidades desses profissionais. Isso pode ser percebido pela valorização da experiência em cargos de gerência, tendo em vista que atualmente (julho de 2019) $59,4 \%$ dos EPPGG possuem cargos comissionados ou funções gratificadas, muitas delas relacionadas a cargos de gerência. Ocorreu ainda a valorização de atividades acadêmicas, já que os gestores reconhecem que a carreira de EPPGG se trata de profissionais que valorizam a formação continuada.

Essa valorização de critérios acadêmicos e gerenciais para os processos de promoção e progressão foram sinalizados pelos EPPGG como medidas importantes, nas entrevistas realizadas em 2009. 
Destaca-se ainda a inserção de mais um nível na carreira de EPPGG, que passa de quatro para cinco níveis, e a diminuição do tempo para promoção, que mudou de cinco anos para quatro anos. Ambas se configuram como alterações na estrutura da carreira, facilitando a promoção, critérios esses indicados pelos entrevistados como motivos para a evasão. Outra importante iniciativa foi a criação do Núcleo de Gestão da Carreira de EPPGG², unidade gerencial presente na estrutura organizacional da Secretaria de Planejamento e Gestão. Instituído pelo Decreto no 46.557, de 11 de julho de 2014, o núcleo tem por finalidade gerir, apoiar a alocação e promover a gestão da carreira do EPPGG. A criação do núcleo também sinaliza a diferenciação dessa carreira em relação às demais, além de possibilitar uma gestão mais individualizada desses profissionais.

Uma das atuações do núcleo se refere à gestão da mobilidade da carreira de EPPGG, já que para esses profissionais se movimentarem nos diferentes órgãos do Estado é necessária autorização do núcleo. Nesse processo, busca-se conciliar o interesse do EPPGG, do órgão de origem e de destino, além de uniformizar as decisões quanto à alocação, medidas demandadas pelos EPPGG entrevistados em 2009. Embora ainda haja reclamações quanto a esse processo, a comparação quanto à distribuição dos EPPGG nos órgãos estaduais, considerando o ano de 2008 e 2019 (Tabela 7), permite verificar uma melhor distribuição dos EPPGG, o que pode sinalizar mudanças positivas no processo de mobilidade e alocação.

Tabela 7 | Órgão de alocação, nos períodos de 2009 e 2019

\begin{tabular}{|l|c|c|c|}
\hline Órgão- $\mathbf{2 0 0 9}$ & $\%$ & Órgão - 2019 & $\%$ \\
\hline SEPLAG & $42,6 \%$ & SEPLAG & $30,7 \%$ \\
\hline SEGOV & $7,0 \%$ & SEDESE & $6,2 \%$ \\
\hline SEF & $4,7 \%$ & SES & $5,5 \%$ \\
\hline SEDS & $4,7 \%$ & SEDE & $4,6 \%$ \\
\hline SES & $4,7 \%$ & FJP & $3,6 \%$ \\
\hline
\end{tabular}

\footnotetext{
${ }^{2}$ Em janeiro de 2018, o Decreto no 47.337 de 12 de janeiro de 2018 criou o Núcleo de Integração e Desenvolvimento de Pessoas (Nidep) em substituição ao Núcleo de Gestão da Carreira de Especialista em Políticas Públicas e Gestão Governamental (EPPGG). Esse núcleo, que antes tinha a atribuição de gestão apenas da carreira de EPPGG, teve suas atribuições ampliadas para a gestão das outras carreiras da Seplag. No artigo 37 do referido decreto, estabelece-se a competência do núcleo em viabilizar e implementar as soluções de gestão de pessoas dos servidores em exercício na Seplag, bem como dos integrantes da carreira de Especialista em Políticas Públicas e Gestão Governamental - EPPGG.
} 


\begin{tabular}{|l|c|c|c|}
\hline SETOP & $4,7 \%$ & SEDPAC & $3,5 \%$ \\
\hline Demais órgãos (24) & $31,8 \%$ & Demais órgãos (42) & $45,8 \%$ \\
\hline Total & $100 \%$ & Total & $100 \%$ \\
\hline
\end{tabular}

Fonte: dados da pesquisa ${ }^{3}$

Conforme demonstra a Tabela 7, havia em 2009 uma grande concentração dos EPPGG na Seplag, o que era motivo de reclamação por esses profissionais, e essa era justificada pelos gestores com o fato de que esse órgão era o responsável pela gestão do programa de governo, denominado Choque de Gestão, que se propunha a modernizar os órgãos da administração pública mineira, por meio da adoção de uma gestão por resultados e pela inovação administrativa. Por esse motivo, esse órgão demandaria uma quantidade maior de especialistas.

A Tabela 7 mostra que o órgão que detém maior número de EPPGG continua sendo a Seplag; porém, duas questões merecem destaque: a primeira delas é que esse percentual reduziu-se de $42,6 \%$ para $30,7 \%$. A segunda, que é possível perceber uma maior diversificação dos órgãos nos quais os EPPGG são alocados. Em 2009, os membros da carreira estavam alocados em 30 órgãos da administração direta e indireta do Estado de Minas Gerais, enquanto que em 2019 esses estão distribuídos em 54 órgãos. Essa diversificação também pode sinalizar uma melhor gestão da alocação e das possibilidades de mobilidade dos EPPGG, item considerado em 2009 como um dos motivos para a evasão desses profissionais da carreira.

No que tange às questões salariais, tem-se que em 2012 também foi aprovado pelo Governo de Minas Gerais um aumento escalonado concedido durante 3 anos, entre 2012 e 2014, autorizado pela Lei no 20.336, de 02/08/2012. Assim, comparando os valores da remuneração, parte fixa e variável, de 2012 e os valores recebidos a partir de agosto de 2014, os aumentos variaram entre 57,31\% e 124,11\%. Ademais, em 2014, a Lei no 21.334, de 26/06/2014, concedeu um novo aumento escalonado que foi concedido nos anos de 2015, 2016 e 2017, que significou um aumento médio de 62\% no valor da remuneração dos EPPGG. Trata-se de medidas posteriores à Lei no 18.974/2010, mas que se configuram

\footnotetext{
${ }^{3}$ Seplag: Secretaria de Planejamento em Gestão; Segov: Secretaria de Governo; SEF: Secretaria de Fazenda; SEDS: Secretaria de Defesa Social; SES: Secretaria de Saúde; Setop: Secretaria de Transportes e obras públicas; Sedese: Secretaria de Desenvolvimento Social; SEE: Secretaria de Estado de Educação; FHEMIG: Fundação Hospitalar de Minas Gerais.
} 
como importantes para a discussão acerca da retenção do EPPGG, tendo em vista que, juntamente com a inadequada estrutura na carreira, a questão salarial foi apontada como o principal motivo para a evasão dos EPPGG, apresentação de relação de dependência com a permanência na carreira.

Atualmente, a remuneração dos EPPGG é composta por uma parte fixa referente ao vencimento básico do cargo, que varia de acordo com o nível e grau da carreira, e por uma parte variável, referente à Gratificação por Desempenho e Produtividade Individual (GDPI), que varia conforme o resultado obtido pelo EPPGG em sua avaliação de desempenho. Enquanto em 2009 76\% dos EPPGG recebiam entre $\mathrm{R} \$ 2.800,00$ e R\$4.000,00, em 2019 a média das remunerações é de $\mathrm{R} \$$ 12.178,45, conforme dados do Portal da Transparência de Minas Gerais.

Além disso, no que se refere à análise da compressão salarial, considerando os valores iniciais e finais dessa remuneração, tem-se uma diferença de 406\%, o que sinaliza uma descompressão salarial. A compressão salarial, conforme discutido anteriormente, se conformava como um dos principais problemas para a evasão dos EPPGG em 2009, e com os reajustes feitos da remuneração desses profissionais desde 2012, observa-se que tal problema também foi solucionado.

Porém, cabe destacar que há autores, como Longo (2007), que afirmam que uma diferença entre o salário final e inicial acima de 200\% pode significar uma excessiva descompressão salarial. Tal situação indicaria um sistema cativo de algumas elites profissionais e refletiria um grau mais ou menos elevado de iniquidade interna da estrutura de compensação.

É provável que essa melhoria na remuneração tenha impactado significativamente a concessão de cargos comissionados para os ocupantes do cargo de EPPGG, já que, a partir de dados do Portal da Transparência referentes a julho de 2019, em torno de 59,4\% dos EPPGG possuem cargos comissionados, incluindo as funções gratificadas. Embora esse seja um percentual ainda significativo, é inferior aos 70,5\% encontrados em 2009. Tal situação reforça a percepção dos entrevistados à época de que a concessão desses cargos não estava estritamente relacionada ao desempenho dos EPPGG ou à efetiva ocupação de funções mais estratégicas ou de maior responsabilidade, mas, sim, a uma inadequada 
estrutura salarial da carreira. Com a melhora da estrutura de carreira e salarial é possível diminuir a concessão desses cargos.

Diante disso, pode-se dizer que as medidas implementadas pela Lei $n-18.974 / 10$, influenciaram a retenção dos EPPGG, tendo em vista que redefiniram os procedimentos para o desenvolvimento dentro da carreira, além de terem promovido mudanças na estrutura remuneratória. Tal afirmação pode ser realizada a partir da constatação de que as principais mudanças trazidas pela referida lei estavam intimamente relacionadas aos principais motivos de evasão dessa carreira. Tais impactos podem explicar a redução dos índices de evasão entre os períodos analisados, conforme demonstra a Tabela 8.

Tabela 8 | Comparativo dos percentuais de evasão entre os anos de 2009 e 2019

\begin{tabular}{|c|c|c|c|c|}
\hline Ano & $\begin{array}{c}\text { Total de egressos do } \\
\text { Csap ingressantes na } \\
\text { carreira de EPPGG }\end{array}$ & $\begin{array}{c}\text { Total de } \\
\text { membros da } \\
\text { carreira }\end{array}$ & $\begin{array}{c}\text { Total de } \\
\text { exonerados }\end{array}$ & \% de evasão \\
\hline 2009 & 465 & 298 & 167 & $\mathbf{3 5 , 9 \%}$ \\
\hline 2019 & 1029 & 696 & 333 & $\mathbf{3 2 , 4 \%}$ \\
\hline
\end{tabular}

Fonte: elaborado pelos autores em 2019.

Apesar de o percentual de evasão observado em 2019 ainda se apresentar em um patamar significativo, observa-se a redução do índice em relação a 2009, que pode ser atribuída às mudanças realizadas na gestão da carreira de EPPGG.

Tal afirmação pode ser realizada, tendo em vista que as principais variáveis que levavam à evasão em 2009, a saber ausência de mobilidade, falhas nos processos de promoção e progressão, ausência de capacitação e inadequação da remuneração, tiveram suas políticas aprimoradas, a partir da Lei no 18.974/2010.

\section{Considerações finais}

O objetivo deste trabalho consistiu em analisar a carreira de EPPGG de Minas Gerais a partir dos principais motivos que levavam à evasão dos EPPGG até o ano de 2009, bem como as mudanças introduzidas a partir da Lei no 18.974/2010 e sua influência na retenção dos EPPGG. 
Por meio da pesquisa realizada em 2009, verificou-se que tanto os exonerados quanto os EPPGG entrevistados consideraram a questão salarial e a estrutura de carreira como principais fatores que levavam à evasão. Sobre esses motivos de evasão, destacamse os seguintes problemas: estrutura salarial inadequada e insatisfatória; distorção salarial quanto à outras carreiras públicas; compressão vertical e horizontal dos salários; e dificuldade de progressão e promoção na carreira.

Esses problemas estavam relacionados, na perspectiva dos EPPGG, ao fato de que grande parte das políticas e práticas de gestão de pessoas implementadas pelo Estado de Minas Gerais, até o ano de 2009, foi implementada de maneira uniforme para todos os servidores do estado. Nesse contexto, alguns EPPGG reclamavam por uma diferenciação no tratamento concedido a eles, por se tratar de uma carreira difundida pelos gestores como estratégica para o governo de Minas Gerais. Nesse caso, pôde-se perceber que os EPPGG esperavam, não apenas que a estrutura da carreira e salarial fosse diferenciada, mas também que outros instrumentos de $\mathrm{RH}$, tais como a avaliação de desempenho e a promoção e progressão na carreira, tivessem critérios distintos, mais bem adequados às suas especificidades.

A partir de 2010, o Estado de Minas Gerais conseguiu, de fato, conferir um caráter estratégico à carreira de EPPGG, tendo em vista que, a partir das mudanças introduzidas, possibilitou uma gestão diferenciada da carreira. Aliou-se o caráter inovador e pioneiro da seleção e formação dos EPPGG, materializado a partir do Csap, com o caráter inovador na gestão da carreira, ao estruturar um desenho e trajetória de carreira que valoriza diversos aspectos da vida profissional, além de promover equidade externa.

Assim, as medidas estimularam o desenvolvimento na carreira, sinalizando uma diferenciação na gestão desses profissionais, vista como fundamental pelos EPPGG entrevistados.

A articulação de uma seleção e formação de qualidade com uma gestão de carreira adequada, considerando o arcabouço teórico utilizado, nos permite afirmar que a carreira de EPPGG em Minas Gerais constitui um importante projeto de profissionalização da gestão pública. Enquanto uma iniciativa inovadora, esse projeto passou por reajustes e transformações ao longo dos anos, em busca da efetividade da política. Tais adequações são esperadas quando se trata de ações pioneiras. 
De acordo com Klein e Mascarenhas (2016), a carreira de EPPGG em âmbito federal e em diversos Estados, tais como Espírito Santo, Mato Grosso e Rio de Janeiro, incluindo Minas Gerais, ocorre em meio à tentativa de se implementar uma agenda reformista que contemplava, além da mudança cultural, a promoção de uma gestão por resultados, a melhoria da qualidade do serviço público, bem como a satisfação das necessidades sociais. A análise das mudanças realizadas na gestão da carreira de EPPGG em busca de uma maior retenção desses profissionais nos mostra uma preocupação do estado na busca desses objetivos.

Diante dessa mudança, observa-se a redução do percentual de evasão de $35,9 \%$ para $32,4 \%$. Tendo em vista ainda se tratar de um índice significativo, sugere-se pesquisas futuras que aprofundem o entendimento do atual índice de evasão, tentando analisá-lo sob diversos aspectos e variáveis, tais como organizacionais, econômicos e políticos, no sentido de identificar quais outros fatores podem impactar a evasão, para além daqueles identificados em 2009. Tal análise é importante para que o Estado de Minas Gerais possa refletir acerca de novas mudanças que possam ser implementadas. Essa análise é relevante também para outros Estados que possuem carreiras semelhantes.

Por fim, pode-se dizer que o desafio atual gira em torno de aproximar a carreira de EPPGG das demais carreiras do Estado de Minas Gerais, já que é possível observar certa resistência por parte da burocracia estatal, e também por parte de outras carreiras do Estado de Minas Gerais, em relação à carreira de EPPGG e a atuação de seus membros. Tal situação é compreensível, tendo em vista que as melhorias realizadas na carreira de EPPGG desde 2010 não foram visualizadas em outras carreiras do estado que também possuem significativa relevância para a qualidade do serviço público mineiro.

Além disso, conforme afirmam Klein e Machado (2016), a consolidação da carreira de EPPGG nos governos estaduais possui um desafio contínuo, já que, de maneira geral, significa a inserção de uma carreira mais voltada para a inovação e para os fins das políticas públicas em uma estrutura burocrática muitas vezes apegada aos meios e aos procedimentos legais, sendo essa carreira ou capturada pela burocracia, ou mesmo hostilizada por essa. 


\section{Referências bibliográficas}

ABRUCIO, F. L. O impacto do modelo gerencial na administração pública: um breve estudo sobre a experiência internacional recente. Cadernos Enap, Brasília, n. 10, p. 52, 1997.

Trajetória recente da gestão pública brasileira: um balanço crítico e a renovação da agenda de Reformas. Revista de Administração Pública, Rio de Janeiro, Edição especial comemorativa, p. 67-86, 2007.

Afonso, V. Inserção e atuação dos egressos do Curso Superior de Administração Pública no Poder Executivo estadual: uma análise do caso mineiro. 2001. Monografia em Administração Pública. Escola de Governo Professor Paulo Neves de Carvalho da Fundação João Pinheiro. Belo Horizonte. 2001.

BARRETO, C. C. P. Atração e retenção de talentos em empresas de engenharia consultiva no setor de petróleo e gás natural da cidade de Natal. Dissertação de mestrado em administração. Ciências Sociais Aplicadas. Universidade Federal do Rio Grande do Norte. Natal. 2008.

BRUGUÉ, Q. Modernizar la administración desde la izquierda: burocracia, nueva gestión pública y administración deliberativa. Revista del CLAD Reforma y Democracia. Caracas. n. 29, 2004.

CARNeIRO, R.; MenICUCCI, T. M. G. Gestão pública no século XXI: as reformas pendentes. Texto para discussão 1686. Brasília, Ipea, 2011.

CRUz, R. M. S. G. A evasão dos administradores públicos em Minas Gerais. Dissertação de Mestrado. Programa de Mestrado em Administração Pública. Escola de Governo Professor Paulo Neves de Carvalho, Fundação João Pinheiro, Belo Horizonte, Brasil, 2005.

COELHO, F. S. A problemática atual do ensino de graduação em administração pública no Brasil. Cadernos EBAPE, Número especial, agosto, 2008.

DANCEY, C.P. Estatística sem matemática para a psicologia. Porto Alegre: Artmed, 2006

Denhardt, R. B; Denhardt, J. V. The New Public Service: Serving rather than steering. Public Administration Review, v. 60, Issue 6, p. 549-559, November/December, 2000.

DUNZER, G.A et.al Desafios de atração e retenção de talentos: estudo de caso da Petrobras. In: Encontro Nacional de Administração da Anpad, 32, 2008, Rio de Janeiro, Anais do Congresso. Rio de Janeiro: Anpad, 2009.

FARIA, M. B. et. al Profissionalização da gestão pública: o caso de uma IFES Sul Mineira. In: Colóquio de Gestão Universitária, 12, 2012, Santa Catarina. Anais do Congresso. Santa Catarina, 2009. Disponível em https://repositorio.ufsc.br/handle/123456789/97793. Acesso em: 15 de março de 2016.

FerReIRA, C. M. M. Crise e Reforma do Estado: uma questão de cidadania e valorização do servidor. In: PETRUCCI, Vera; SCHWARZ, Letícia (orgs). Administração pública gerencial: a reforma de 1995. Brasília: Editora Universidade de Brasília: Enap, cap. 2, p. 63-96, 1999. 
FigueroA, R. Régimenes de directivos públicos en América Latina: estado del arte, análisis y perspectivas. Washington: Banco Interamericano de desenvolvimento (BID), 2002.

GAETANI, F. Capacitação de recursos humanos no serviço público: problemas e impasses. Revista do Serviço Público, Brasília, Enap, 1998.

GOMES, E. G. M. Gestão por resultados e eficiência na administração pública: uma análise à luz da experiência de Minas Gerais. Tese de Doutorado, Escola de Administração de Empresas de São Paulo, Fundação Getúlio Vargas, São Paulo, SP, Brasil, 2009.

HORTA, C. J. G. et. al Análise das mudanças no perfil socioeconômico dos interessados na formação para a área pública: estudo aplicado aos vestibulandos e alunos do curso de graduação da Escola de Governo da Fundação João Pinheiro. Revista Temas de Administração Pública. Edição Especial, n.6, v. 2. 2011.

KLEIN, F. A.; MASCARENHAS, A. O. Motivação, satisfação profissional e evasão no serviço público: o caso da carreira de especialistas em Políticas Públicas e Gestão Governamental. Revista de Administração Pública, Rio de Janeiro, jan. /fev. 2016.

Longo, F. Mérito e flexibilidade: a gestão das pessoas no setor público. São Paulo: Fundap, 2007.

Minas Gerais. Decreto no 46.557, de 11 de julho de 2014. Dispõe sobre a organização da Secretaria de Estado de Planejamento e Gestão. Assembleia Legislativa.

Minas Gerais. Lei no 13.085, de 31 de dezembro de 1998. Cria as carreiras que menciona, institui a gratificação de desempenho e produtividade individual e institucional e dá outras providências. Assembleia Legislativa

MinAS GeRAIS. Lei no 15.304, de 11 de agosto de 2004. Reestrutura a carreira de especialista em políticas públicas e gestão governamental e institui a carreira de auditor interno do Poder Executivo. Assembleia Legislativa.

Minas GeraIs. Lei no 18.974, de 29 de junho de 2010. Estabelece a estrutura da carreira estratégica de especialista em políticas públicas e gestão governamental e dá outras providências. Assembleia Legislativa.

MinAS GeraIS. Lei no 20.336, de 02 de agosto de 2012. Promove a incorporação de parcela da GEDIMA a vencimento básico dos servidores das carreiras do Instituto Mineiro de Agropecuária IMA -, reajusta as tabelas de vencimento básico da carreira de auditor interno do Poder Executivo, altera as Leis no 15.463, de 13 de janeiro de 2005, e 18.974, de 29 de junho de 2010, e dá outras providências. Assembleia Legislativa.

Minas GeraIS. Lei no 21.334, de 26 de junho de 2014. Altera as Leis Delegadas № 39, de 3 de abril de 1998, e 174, de 26 de janeiro de 2007, e a Lei n 11.406, de 28 de janeiro de 1994, e dá outras providências. Assembleia Legislativa.

MoTA et. al Fatores que afetam a rotatividade e evasão de talentos na administração pública brasileira - o caso dos gestores públicos. In: Congresso Consad de Gestão Pública, 9, 2016, Brasília. Anais do Congresso. Disponível em http://consad.org.br/wp-content/uploads/2016/06/ Painel-02-01.pdf. NogueIRA, R. P; SANTANA, J. P. Human Resource Management and public sector reforms: trends and origins of a new approach. IPEA. Texto para discussão, n. 888. Brasília. 2002. 
OCDE. Organização para Cooperação e Desenvolvimento EConômico. Recent developments and future challenges in human resource management in OECD member countries background paper by the secretariat. Paris, July 2000.

OliveirA, K. P et. al Retenção de pessoas no setor público mineiro: o caso dos especialistas em políticas públicas e gestão governamental. ReCaPe. Revista de Carreiras e Pessoas. São Paulo, v.02, n.03, Set/Out/Nov/Dez, 2012.

PACHECO, R. S. Profissionalização, mérito e proteção da burocracia no Brasil. In: ABRUCIO, F. L; LOUREIRO, M. R; PACHECO, R. S. Burocracia e política no Brasil: desafios para o Estado democrático no século XXI. São Paulo: Editora FGV, 2010.

PAULA, A. P. P. Administração pública gerencial e construção democrática no Brasil: uma abordagem crítica. In: Encontro Nacional dos Programas de Pós-Graduação em Administração, 25, 2001, Rio de Janeiro. Anais do Congresso. Rio de Janeiro: Anpad, 2001.

PAULA, A. P. P. Por uma nova gestão pública: limites e potencialidades da experiência contemporânea. Rio de Janeiro: EdFGV. 2005.

PEREIRA, L. C. B. Reforma do Estado para a cidadania: a reforma gerencial brasileira na perspectiva internacional. São Paulo: Ed. 34; Brasília: Enap, 1998.

RAMIÓ, C.; SALVADOR, M. Intituciones y reforma del sector público: el impacto de los referentes institucionales en la gestión de recursos humanos de las administraciones públicas latinoamericanas. In: LONGO, F.; RAMIó, C. (Ed). La profissionalización del empleo público en América Latina; Barcelona: Fundación CIDOB, 2008.

RHODES, R. A. W. The New Governance: governing without government. Political Studies. Volume 44, Issue 4, pages 652-667, 1996.

SILVA, E. M. Os efeitos da liderança na retenção de talentos um estudo sobre comprometimento e rotatividade numa indústria petroquímica. Dissertação de Mestrado. Faculdade de Economia e Finanças Ibmec. Rio de Janeiro. 2006

VIANA, J. Mais que administrar, cuidar! Revista do Serviço Público, de 1937 a 2007, Edição especial, Brasília, p. 49, 2007.

YIN, R. K. Estudo de caso: planejamento e métodos. Tradução: Ana Thorell; revisão técnica: Cláudio Damacena. 4ạ ed. Porto Alegre: Bookman, 2010. 


\section{Kamila Pagel de Oliveira}

Orcid: 0000-0002-6183-2041

Doutora e Mestre em Administração pela UFMG. Graduada em Administração Pública pela Escola de Governo da Fundação João Pinheiro (FJP). Docente do Programa de Mestrado e Graduação da FJP. Especialista em Políticas Públicas e Gestão Governamental de Minas Gerais. Escola de Governo da Fundação João Pinheiro, Belo Horizonte, MG.

E-mail: kamilapagel84@gmail.com

\section{Ivan Beck Ckagnazaroff}

(iD) Orcid: 0000-0002-8179-269X

Belo Horizonte, MG

Prof. Titular do departamento de Ciências Administrativas, do Centro Pós-graduação e Pesquisa em Administração da Faculdade de Ciências Econômicas da Universidade Federal de Minas Gerais (UFMG). Área de interesse: governança pública, gestão de políticas públicas, reforma administrativa.

E-mail: ivanbeck00@gmail.com.

\section{Mauro César da Silveira}

(iD) Orcid: 0000-0001-7502-6553

Doutor em Administração CEPEAD/ UFMG, Mestre em Engenharia de Produção (UFMG), graduado em Direito (UFJF) e Administração (FCAMS). Atualmente é Gerente de Extensão e Relações Institucionais da Fundação João Pinheiro e professor desta instituição.

E-mail: maurocsilveira75@gmail.com 